\title{
Scievced corferptrates
}

\section{Chiral Inversion of Gold Nanoparticles}

C. Gautier and T. Bürgi*, J. Am. Chem. Soc. 2008, 130, 7077

University of Neuchâtel

The chirality of extended metal surfaces and of their nanometer size analogous, metallic nanoparticles (NPs), has become an emerging field of research in recent years. In this article, a thiolatefor-thiolate ligand exchange was performed on well-defined gold nanoparticles under an inert atmosphere without modification of the core size. As a chiral enantiopure thiol is exchanged for its opposite enantiomer, the optical activity in metal-based electronic transitions is reversed although the form of the CD spectra remains largely unchanged. This shows that the chiral arrangement of metal atoms in the metal particle cannot withstand the driving force imposed by the ligand of opposite absolute configuration.

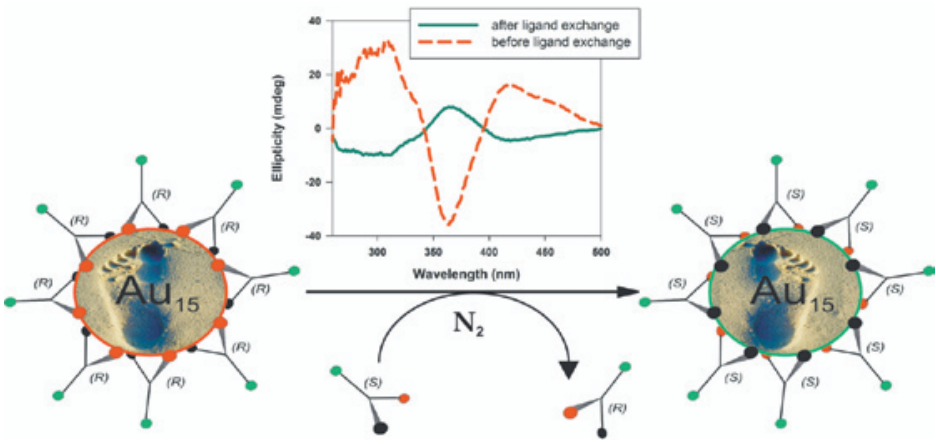

Influence of Amino Acid Side Chains on Long-Distance Electron Transfer in Peptides: Electron Hopping via 'Stepping Stones'

M. Cordes, A. Köttgen, C. Jasper, O. Jacques, H. Boudebous, and B. Giese*, Angew. Chem., Int. Ed. 2008, 47, 3461

University of Basel

Electron transfer (ET) processes through proteins play an important role in many biological reactions. In this paper, it is shown that the mechanism of this ET depends upon the side chain X located between the electron donor and the electron acceptor. Electron transfer occurs either by a slow single-step superexchange or by a two-step hopping process that is 20-30-times faster (see Scheme). All intermediates in the hopping process could be observed simultaneously.

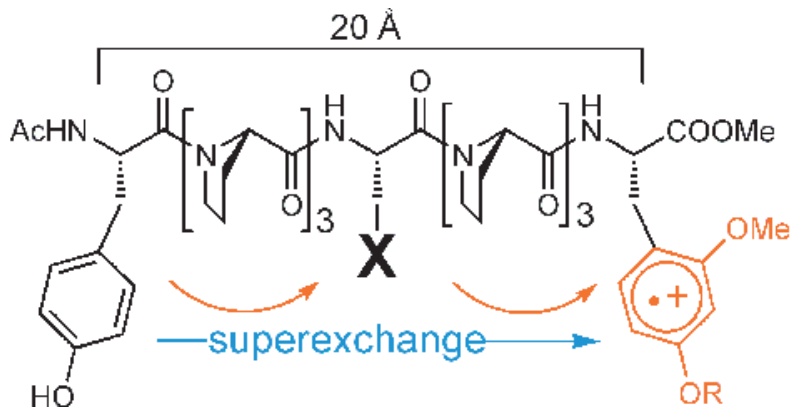

\section{Unravelling the Shuttling Mechanism in a Photoswitchable Multicomponent Bistable Rotaxane}

P. Raiteri*, G. Bussi, C. S. Cucinotta, A. Credi*, J. F. Stoddart, and M. Parrinelo, Angew. Chem., Int. Ed. 2008, 47, 3536

ETH Zurich; Università di Bologna; UCLA

This article describes the results of a computational investigation on the operation mechanism of a photoswitchable bistable rotaxane that in solution functions as an autonomous molecular shuttle powered by visible light. The free-energy calculations confirm the experimental observations on the relative stability of the different co-conformations of the bistable rotaxane. The most remarkable finding is that decomplexation of the counteranions from the cationic stations may limit the rate of the ring shuttling process - and hence the efficiency of the nanomachine.

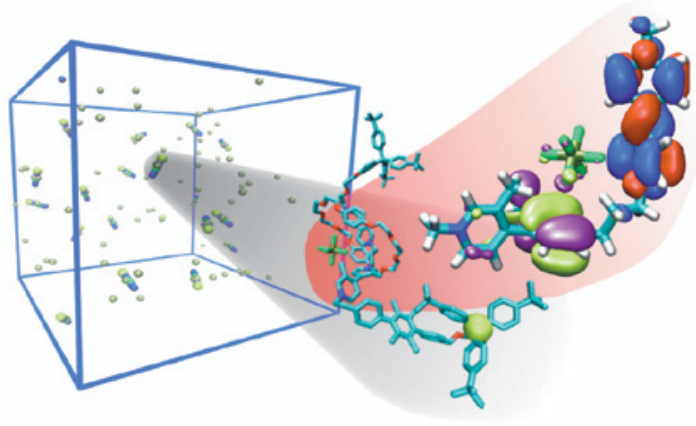

\section{The 'Complex-in-a-Complex' Cations [(acac) $)_{2} \mathbf{M} \subset \mathbf{R u}_{6}$ $\left.\left(p-i \mathrm{PrC}_{6} \mathrm{H}_{4} \mathrm{Me}\right)_{6}(\mathrm{tpt})_{2}(\mathrm{dhbq})_{3}\right]^{6+}:$ A Trojan Horse for Cancer Cells}

B. Therrien*, G. Süss-Fink, P. Govindaswamy, A. K. Renfrew, and P. J. Dyson, Angew. Chem., Int. Ed. 2008, 47, 3773

University of Neuchâtel; EPF Lausanne

'Complex-in-a-complex' cations $\left[(\mathrm{acac})_{2} \mathrm{M} \subset \mathbf{1}\right]^{6+}(\mathrm{M}=\mathrm{Pd}, \mathrm{Pt}$; acac $=$ acetylacetonato ) have been obtained by the authors from the assembly of cationic hexanuclear metalloprism $\left[\mathrm{Ru}_{6}(p-\right.$ $\left.\left.i \operatorname{PrC}_{6} \mathrm{H}_{4} \mathrm{Me}\right)_{6}(\mathrm{tpt})_{2}(\mathrm{dhbq})_{3}\right]^{6+}(\mathbf{1})$ in the presence of $\left[\mathrm{M}(\mathrm{acac})_{2}\right]$. The cytotoxicity of both supramolecular species was evaluated in comparison with the empty cage and free $\left[\mathrm{M}(\mathrm{acac})_{2}\right]$. The higher toxicity of the 'complex-in-a-complex' derivatives suggests that, like a 'Trojan Horse', the release of the guest from the cages once inside a cell accelerates and increases the cytotoxic effect.

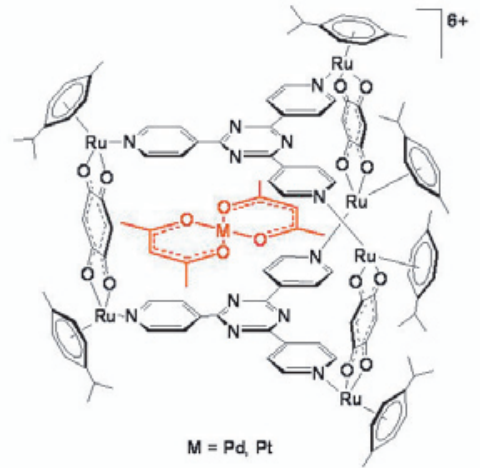

Prepared by Martina Austeri, Renaud Bach, Nathalie Mehanna, Roman Novikov, Ankit Sharma, Franck Torricelli, Jérôme Lacour Do you want your article to appear in this SWISS SCIENCE CONCENTRATES highlight?

Please contact concentrates@chimia.ch 